\section{Percutaneous Endoscopic Gastrostomy/Jejunostomy in the Early Postoperative Period}

The principal indications for percutaneous endoscopic gastrostomy (PEG) (1) or gastrojejunostomy (PEGJ) are long-term enteral nutrition and decompression of the gastrointestinal tract (2). We found that PEG/PEGJ may also be of value in the treatment of certain postoperative complications $(3,4)$. Two cases of unusual early postoperative complications are reported here.

Case 1. PEGJ for the treatment of an external gastric fistula. A 53-year-old woman suffering from a pseudocyst underwent pancreatic resection. Acute pancreatitis developed for the first time, followed by recurrent retroperitoneal erosive and gastrointestinal bleeding, suture line insufficiency and severe sepsis, coagulopathy and multiple organ failure. After repeated laparatomies, an abdominal wall necrosis, requiring surgery and finally an external ventricular fistula, developed. No further surgery was then feasible. To achieve decompression of the stomach, a suction drain was inserted into the fistula and a Freka-PEG intestinal set (Fresenius Co.) was inserted into the bowel to make nutrition possible (Figure 1). The location of the insertion site was determined fluoroscopically, as the standard transillumination method could not be used due to multiple scars from previous operations. Feeding started 24 hours later via the PEGJ. Nutrition was continued for 80 days via this route, when the fistula occluded spontaneously; after removal of the PEGJ the patient was discharged home.

Case 2. PEG and PEGJ performed in a case of suture line insufficiency. A 67-year-old man underwent a Whipple operation for pancreatic cancer. Partial insufficiency of the choledochojejunostomy developed postoperatively. Re-laparotomy and abdominal drainage were performed. As no tendency for spontaneous occlusion of the fistula could be observed, a double FrekaPEG system was inserted: one for ventricular decompression and gastric juice removal and one for enteral nutrition. The puncture sites for insertion were again determined fluoroscopically (Figures 2,3). Suction was started immediately, and feeding 24 hours later. The suture line insufficiency occluded spontaneously. In spite of our efforts, however, the patient died of cardiopulmonary complications six weeks later.

Thus, PEG and PEGJ may be regarded as successful methods for treating postopera-

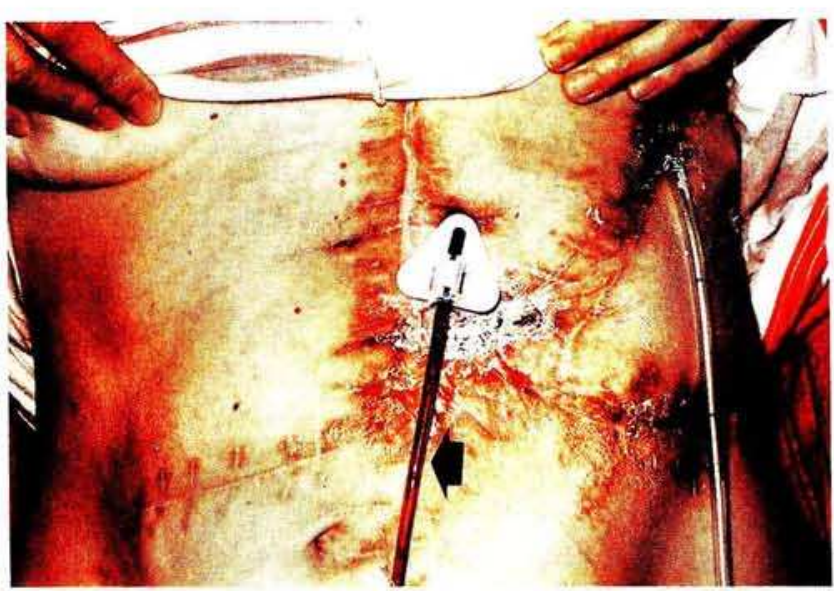

Figure 1: Numerous surgical scars are visible on the abdomina wall. The solid arrow indicates the PEGJ, and the open arrow shows the drain inserted into the external gastric fistula.

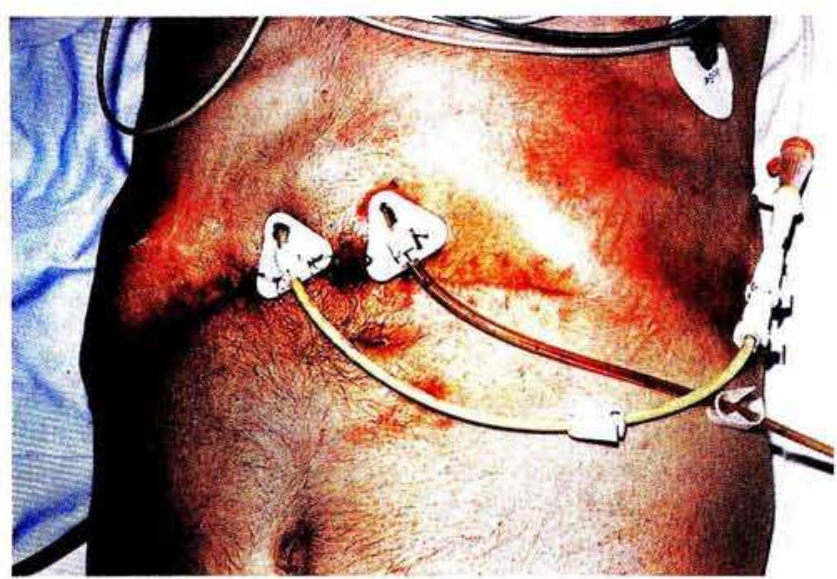

Figure 2: The PEG and PEGJ tubes are seen beside the surgical scars on the abdominal wall.

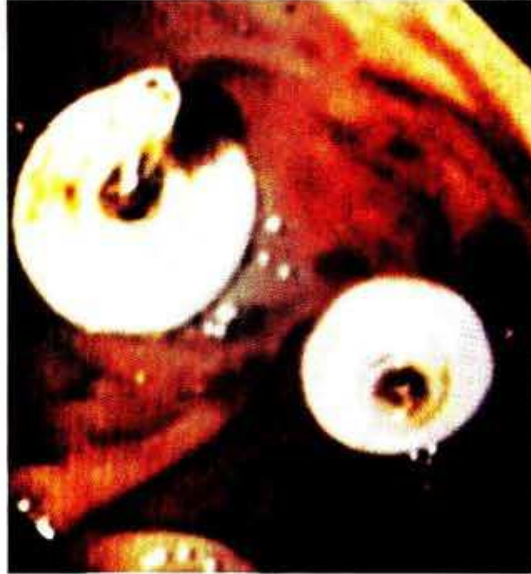

Figure 3: Endoscopic view of the silicon disks fixing the internal position of the PEG and PEGJ.

tive complications, since continuous gastric decompression and adequate long-term enteral nutrition were possible. We would recommend the method for the treatment of such cases.

I, Szántó', A. Vörös', K. Nagy', J. Kiss ' L. Vimláti ', A. Bohák ${ }^{2}$

'Dept. of Surgery

${ }^{2}$ Dept. of Radiology, Postgraduate Medical School (HIETE), Budapest, Hungary

\section{References}

1. Gauderer MWL, Ponsky JL, Izant RL Jr. Gastrostomy without laparotomy: a percutaneous endoscopic technique. J Pediatr Surg 1980; 15: 872-5.

2. Payne-James J. Enteral nutrition: accessing patients. Nutrition 1992; 8 : 233-9.

3. Stellato TA, Gauderer MWL, Ponsky JL. Percutaneous endoscopic gastrostomy following previous abdominal surgery. Ann Surg 1984; 200: 45-50.

4. Townsend MC, Flancbaum L, Cloutier $\mathrm{CT}$, et al. Early postlaparotomy percutaneous endoscopic gastrostomy. Surg Gynecol Obstet 1992; 174: 46-8.

5. Mellinger JD, Ponsky JL. Percutaneous endoscopic gastrostomy: an overview for 1996. Endoscopy 1996; 28: 66-70.

Corresponding Author

I. Szántó, M.D., Ph.D.

Dept. of Surgery

Postgraduate Medical School

Szabolcs u 35

Budapest 1389

Hungary

Fax: $+36-1-270-2382$ 